\title{
In Vitro Evaluation of Recombinant Bone Morphogenetic Protein-2 Bioactivity for Regenerative Medicine
}

\author{
Stephanie L. Fung, BS, ${ }^{*}$ Xiaohuan Wu, BS, ${ }^{\star}$ Julian P. Maceren, Yong Mao, PhD, and Joachim Kohn, PhD
}

Recombinant human bone morphogenetic protein-2 (rhBMP-2) is a commonly used growth factor in bone regeneration due to its high potency and ability to induce osteogenic differentiation of osteoblasts and osteoblast precursors. When designing delivery systems for rhBMP-2, the activity of the loaded and released protein is an important consideration. The variability in the experimental design parameters used to measure rhBMP-2 activity in vitro has precluded comparative analysis. Here, for the first time, we report a direct comparison of the assay parameters used in rhBMP-2 bioactivity assays in the literature and an evaluation of commercially available rhBMP-2 obtained from different vendors. Most published rhBMP-2 assays use W-20-17 (mouse stromal), MC3T3 (preosteoblast), or $\mathrm{C} 2 \mathrm{C} 12$ (myoblast) cell lines. We found that each model cell line has an optimal concentration range over which it is most sensitive to rhBMP-2 induction. Therefore, it is difficult to find one single bioassay protocol that could be universally used. In addition, we established a correlation between protein concentration (as measured by enzyme-linked immunosorbent assay) and protein activity (as measured by alkaline phosphatase induction). We found that the expression system used to produce the rhBMP-2 had the greatest effect on its activity and stability in vitro. Establishing a standard method of measuring rhBMP-2 activity in vitro is the first step toward developing an in vitro-in vivo correlation between measured activity and clinical outcomes.

Keywords: BMP-2, bioactivity, alkaline phosphatase activity, bone regeneration

\section{Impact Statement}

This work is a systematic evaluation of the experimental parameters of the most widely used in vitro recombinant human bone morphogenetic protein-2 (rhBMP-2) activity assays. The variations in assays reported in the literature have challenged the reproducibility and translation of work using rhBMP-2 as a bone-inducing growth factor. By elucidating the effect of model cell line on the dose-dependent alkaline phosphatase response to rhBMP-2 induction and by establishing a correlation between protein activity and protein concentration by enzyme-linked immunosorbent assay using commercially available rhBMP-2, this work is a significant step toward developing an in vitro-in vivo correlation between quantified activity and clinical efficacy.

\section{Introduction}

B ONE MORPHOGENETIC PROTEIN-2 (BMP-2) is a strong inducer of osteogenic differentiation. ${ }^{1-4}$ It is currently the only Food and Drug Administration (FDA)-approved osteoinductive factor used clinically for bone fusion applications in the United States. ${ }^{5}$ BMP-2 can be isolated from native bone, or more commonly, expressed as a recombinant human protein (rhBMP-2). The structure and function of the native human BMP-2 have been thoroughly addressed. ${ }^{6}$ Mature, bioactive BMP-2 molecules are in the form of a dimer composed of two monomeric units linked by disulfide bonds. Reduction of these disulfide bonds results in the complete loss of bioactivity. ${ }^{6}$ RhBMP-2 has been shown to increase alkaline phosphatase (ALP) expression through the Wnt signaling pathway in many cell types, making ALP expression a universal marker for measuring rhBMP-2 bioactivity in vitro. ${ }^{7}$

rhBMP-2 can be produced in various expression systems, including a mammalian source, such as the Chinese hamster ovary (CHO) or human embryonic kidney (HEK) cells; or a bacterial source, such as Escherichia coli. ${ }^{7,8}$ Recombinant proteins produced in mammalian cells are glycosylated in their

New Jersey Center for Biomaterials, Rutgers-The State University of New Jersey, Piscataway, New Jersey.

*Authors contributed equally.

(C) Stephanie L. Fung et al., 2019; Published by Mary Ann Liebert, Inc. This Open Access article is distributed under the terms of the Creative Commons License (http://creativecommons.org/licenses/by/4.0), which permits unrestricted use, distribution, and reproduction in any medium, provided the original work is properly cited. 
final form, whereas those produced in bacterial cells do not undergo this post-translational modification. ${ }^{8}$

Although it has been reported that glycosylation is not essential for the biological activity of rhBMP-2, ${ }^{9-11}$ the glycosylation influences the biological function of the protein, especially in its effect on interactions between the protein and its carrier and on its distribution once delivered in the body. For example, it was shown that despite small differences in the isoelectric point of the E. coli- and CHOderived rhBMP-2, the pharmacokinetics varied significantly in vivo due to the reduced solubility of nonglycosylated protein. ${ }^{9}$ In the case of rhBMP-2 mixed with a fibrin carrier, the reduced solubility of nonglycosylated rhBMP-2 improved the healing rate of critical-sized defects in a rat calvarial model. ${ }^{11}$

Different cell lines have been used to measure rhBMP-2 bioactivity in vitro. W-20-17 cells are derived from the bone marrow of a $\mathrm{W}^{++}$mouse strain. These cells express low basal levels of ALP; however, upon induction with $>6 \mathrm{ng} / \mathrm{mL}$ rhBMP-2 for $24 \mathrm{~h}$, cells express higher than basal levels of ALP in a dose-dependent manner without an effect on cell proliferation. ${ }^{12}$ The W-20-17 cell line has been used to determine the bioactivity of rhBMP-2 delivered in hydrogels and microspheres, ${ }^{10,13,14}$ and is also the cell line used in the American Society for Testing and Materials (ASTM) Standard Test Method for In vitro Biological Activity of rhBMP-2 (F2131-02).

rhBMP-2 also has the ability to redirect $\mathrm{C} 2 \mathrm{C} 12$ cells, a myoblast cell line, down the osteogenic lineage. ${ }^{1}$ ALP activity, osteocalcin production, and parathyroid hormoneinduced $3^{\prime}, 5^{\prime}$-cAMP production were all upregulated upon incubation with $>100 \mathrm{ng} / \mathrm{mL}$ rhBMP-2, which suggests emergence of an osteoblastic phenotype. These concentrations were also sufficient to inhibit myotube formation. Transforming growth factor beta-1 (TGF- $\beta 1$ ) induction resulted in a decrease in osteocalcin production and ALP activity, which confirms the specificity of rhBMP-2 in converting myoblasts toward the osteoblastic lineage. ${ }^{1}$ Therefore, $\mathrm{C} 2 \mathrm{C} 12$ cells are used as a model cell line to measure rhBMP-2 bioactivity in many studies. ${ }^{15-18}$ Other cells such as osteoblast progenitor cells (MC3T3) have also been used to determine the bioactivity of BMP-2. ${ }^{19-21}$

In this study, we evaluated and compared the sensitivity of the most widely used rhBMP-2 bioactivity assays. We explored the dose response of $\mathrm{W}-20-17, \mathrm{C} 2 \mathrm{C} 12$, and MC3T3 cells to the same batch of rhBMP-2 (E. coli-derived rhBMP-2). Next, we compared the bioactivity and stability of rhBMP-2 from different commercial sources. The results of our systematic study will help researchers to choose an appropriate bioactivity assay based on their research needs.

\section{Materials and Methods}

\section{Cell culture}

C2C12 cells were (ATCC CRL-1772) cultured according to manufacturer's instructions. Cells were maintained in Dulbecco's modified Eagle's medium (DMEM; Life Technologies) containing $10 \%$ fetal bovine serum (FBS; Atlanta Biologicals) and $35 \mu \mathrm{g} / \mathrm{mL}$ gentamicin (Sigma-Aldrich). Cells were passaged before reaching confluence, and medium was changed every 3-4 days. MC3T3-E1 cells (ATCC CRL-2593) were cultured in complete Alpha Minimum Es- sential Medium ( $\alpha$ MEM; Life Technologies) containing $10 \%$ FBS and $35 \mu \mathrm{g} / \mathrm{mL}$ gentamicin. Cells were passaged upon reaching confluence, with media changes every 3-4 days.

W-20-17 cells (ATCC CRL-2623) were cultured according to the ASTM Standard Protocol (F2131-02). Basal medium was prepared by dissolving $13.3 \mathrm{~g}$ of DMEM with $4500 \mathrm{mg} / \mathrm{L}$ glucose and 4.0 mM L-glutamine (Sigma-Aldrich) and $2.226 \mathrm{~g}$ sodium bicarbonate (Sigma-Aldrich) in $800 \mathrm{~mL}$ of purified water. The $\mathrm{pH}$ was adjusted to $7.3 \pm 0.1$ using $0.2 \mathrm{~N} \mathrm{HCl}$, and the final volume was brought to $1 \mathrm{~L}$. The basal medium was then sterile filtered through a $0.2 \mu \mathrm{m}$ PES filter into sterile bottles, and then supplemented with heat-inactivated FBS (10\%), L-glutamine ( $8 \mathrm{mM}$; Life Technologies), and gentamicin $(50 \mu \mathrm{g} / \mathrm{mL})$. Cells with the passage numbers between 3 and 6 were seeded at $2 \times 10^{5}$ cells per T162 flask, and cultured for 4 days before seeding for bioactivity assays. All cells were cultured at $37^{\circ} \mathrm{C}, 5 \% \mathrm{CO}_{2}$, and $>95 \%$ humidity.

\section{BMP-2 sources}

rhBMP-2 were obtained from East China University of Science and Technology (ECUST) or purchased from Peprotech, R\&D Systems, or Humanzyme. The source information for the rhBMP-2 and international standard used is described in Table 1. To dissociate samples from their manufacturers, rhBMP-2 derived from $\mathrm{CHO}$ cells is denoted $\mathrm{C} 1 /$ $\mathrm{C} 2 / \mathrm{C} 3$ in the text. HEK293-derived and E. Coli-derived rHBMP-2 are denoted H1 and E1/E2/E3, respectively. Proteins received as lyophilized powders were reconstituted according to manufacturer's instructions and stored at $-80^{\circ} \mathrm{C}$. Before analysis, concentrations of each stock solution were determined using a microbicinchoninic acid (BCA) kit (Thermo Fisher Scientific) according to manufacturer's instructions. Dilution of each sample was performed based on the concentration determined by BCA assay.

\section{Bioactivity assays}

The protocol for testing in vitro bioactivity of rhBMP-2 using C2C12 cells was adapted from the protocols described in the literature. ${ }^{16}$ Maintenance medium was prepared by

TABle 1. Source Information for Commercially Available Recombinant Human Bone Morphogenetic PROTEIN-2 AND THE INTERNATIONAL STANDARD

\begin{tabular}{llc}
\hline Manufacturer & \multicolumn{1}{c}{ Source } & Lot no. \\
\hline $\begin{array}{l}\text { National Institute for } \\
\text { Biological Standards and } \\
\text { Control, Blanche Lane, }\end{array}$ & CHO cells & N/A \\
$\quad$ United Kingdom & & \\
$\begin{array}{l}\text { PeproTech, Inc., } \\
\quad \text { Rocky Hill, NJ }\end{array}$ & CHO cells & 0215595 \\
$\begin{array}{l}\text { R \& D System, Inc., } \\
\quad \text { Minneapolis, MN }\end{array}$ & CHO cells & MSA5216021 \\
$\begin{array}{l}\text { Medtronic, Minneapolis, MN } \\
\text { Humanzyme, Inc., }\end{array}$ & CHO cells & NEK293 cells \\
$\quad$ Chicago, IL & 0415-01 \\
$\begin{array}{l}\text { ECUST, Shanghai, China } \\
\text { R \& D System, Inc. }\end{array}$ & $\begin{array}{l}\text { Escherichia coli } \\
\text { PeproTech, Inc. }\end{array}$ & $\begin{array}{l}\text { E. coli } \\
\text { N/A }\end{array}$ \\
\hline
\end{tabular}

CHO, Chinese hamster ovary; ECUST, East China University of Science and Technology; N/A, not applicable. 
adding FBS to a final concentration of $2 \%$ in DMEM (Life Technologies). $\mathrm{C} 2 \mathrm{C} 12$ cells were plated at $1 \times 10^{4}$ cells/well in a 96-well tissue culture-treated polystyrene plate (Denville Scientific, Inc.) and cultured in complete growth media (DMEM $+10 \%$ FBS $+35 \mu \mathrm{g} / \mathrm{mL}$ gentamicin) at $37^{\circ} \mathrm{C}$ for $24 \mathrm{~h}$. rhBMP-2 was diluted to $1369 \mathrm{ng} / \mathrm{mL}$ in maintenance media, then serially diluted at 4.3 -fold dilutions (unless otherwise noted) in a 96-well plate. Seven dilutions were prepared.

Growth medium was removed, the monolayer of cells was washed twice with sterile phosphate buffered saline (PBS), and $100 \mu \mathrm{L}$ of maintenance media was added to each well. One hundred microliters of the maintenance media containing rhBMP-2 from the dilution series was added, resulting in the highest concentration of the series being $684.5 \mathrm{ng} / \mathrm{mL}$. Cells were cultured in the absence of rhBMP2 to determine background signal. Cells were incubated at $37^{\circ} \mathrm{C}, 5 \% \mathrm{CO}_{2}$ for $72 \pm 4 \mathrm{~h}$ unless otherwise noted. Medium was removed from all wells. Plate was washed with $200 \mu \mathrm{L}$ PBS. Fifty microliters purified water was added to each well, and the plate was frozen at $-80^{\circ} \mathrm{C}$. Plates underwent two thaw-freeze cycles. The plate was brought to room temperature before development.

The assay mix was prepared by dissolving $170 \mathrm{mg}$ pnitrophenyl phosphate (PNPP) in $50 \mathrm{~mL}$ glycine buffer; the glycine buffer was prepared according to ASTM (F2131-02). Fifty microliters assay mix was added to each well, and the plate was incubated at room temperature on an orbital shaker. Measurements of absorbance at $405 \mathrm{~nm}$ were taken every $30 \mathrm{~min}$ on a Tecan Spark $10 \mathrm{M}$ plate reader (TECAN) until the highest reading of the plate was $\sim 1.0$ optical density greater than the background signal. One hundred microliters $0.2 \mathrm{~N} \mathrm{NaOH}$ was added to each well to stop the reaction. Absorbance was measured again at $405 \mathrm{~nm}$. The dose response of MC3T3-E1 cells to rhBMP-2 induction was assayed using the same methods, with all culture carried out using $\alpha$ MEM in place of DMEM.

The protocol for testing in vitro bioactivity of rhBMP-2 using W-20-17 cells was adapted from the ASTM Standard (F2131-02). Assay medium was prepared by adding FBS (final concentration 10\%), L-glutamine (final concentration $4 \mathrm{mM}$ ), and penicillin/streptomycin (Life Technologies, final concentration $1 \%$ ) to the $\mathrm{W}-20-17$ basal medium described above. W-20-17 cells were plated at $1.0 \times 10^{5}$ cells/ well in $200 \mu \mathrm{L}$ assay medium in a 96-well tissue culturetreated polystyrene plate. rhBMP-2 was diluted as described above. Medium was removed from the monolayer of W-2017 cells, and $200 \mu \mathrm{L}$ of the assay media containing rhBMP-2 was added to each well. Assay medium containing no rhBMP-2 was used as the background sample. Cells were incubated in the presence of rhBMP-2 for $24 \pm 4 \mathrm{~h}$ unless otherwise noted. Takedown of the plates and development were performed as described above.

\section{Modifications to standard protocols}

1. To evaluate the dose response at higher concentrations, rhBMP-2 stocks were diluted to $4096 \mathrm{ng} / \mathrm{mL}$, then diluted twofold to achieve a final concentration range from 1 to $2048 \mathrm{ng} / \mathrm{mL}$.

2. To determine the effect of incubation time on the dose response, incubation times of $24 \mathrm{~h}, 3$ days, and 6 days were tested.

\section{Analysis of data}

The background signal from the samples containing no rhBMP-2 was subtracted from the absorbance value of each test sample. The bioactivity of the sample was determined by fitting the data using a four-parameter logistic equation model, where

$Y=$ measured optical density at $405 \mathrm{~nm}$,

$X=$ concentration of rhBMP -2 ,

$A=$ minimum optical density,

$B=$ slope at the inflection point,

$C=$ ED50 (concentration that reflects that at half of the maximum concentration), and

$D=$ maximum optical density.

MATLAB software (version R2016b; Mathworks) was used for the curve fitting using a modified program.* The upper limits of parameters A, B, C, and D were set at 1, infinity, 1369, and infinity, respectively. Lower limits were not set.

\section{Storage stability}

To examine a correlation between the concentration and bioactivity of rhBMP-2, a $1 \mu \mathrm{g} / \mathrm{mL}$ solution of CHO-derived rhBMP-2 and E.coli-derived rhBMP-2 (E3) was prepared in the assay medium of W-20-17 cells; the stock solution was divided into $500 \mu \mathrm{L}$ aliquots in centrifuge tubes. The aliquots were incubated at $37^{\circ} \mathrm{C}, 5 \% \mathrm{CO}_{2}$, and $\mathrm{RH} 75 \%$. At $6 \mathrm{~h}, 12 \mathrm{~h}$, days $1,2,3,5,7$, and 14, three aliquots were collected and stored at $-80^{\circ} \mathrm{C}$ before enzyme-linked immunosorbent assay (ELISA; PeproTech) and bioactivity assay. The quantified concentrations from ELISA at each time point were normalized to those of day 0 . The bioactivity of rhBMP- 2 at each time point was measured following the procedure from ASTM Standard (F2131-02) with minor modifications, twofold dilutions were performed on each aliquot and incubated with W20-17 cells directly for $24 \mathrm{~h}$.

To evaluate the stability of rhBMP-2 at physiological temperature, a $100 \mathrm{ng} / \mathrm{mL}$ solution, as calculated using BCA assay, of each rhBMP-2 was prepared in the assay media of $\mathrm{W}-20-17$ cells. The stock solution was then aliquoted into $500 \mu \mathrm{L}$ aliquots in centrifuge tubes. The aliquots were incubated at $37^{\circ} \mathrm{C}, 5 \% \mathrm{CO}_{2}$, and $\mathrm{RH} 75 \%$. At days $1,2,3,5,7$, 14, 21, and 28, three aliquots were collected for each rhBMP-2. The samples were stored at $-80^{\circ} \mathrm{C}$ before ELISA (PeproTech). The quantified concentrations at each time point were normalized to those of day 0 .

\section{Statistical analysis}

Single-factor analysis of variance was performed followed by a multiple comparison post-hoc test (Dunnett's test) with an established significance of $p \leq 0.05$. Data were reported as mean \pm standard error. All statistical analyses were carried out in GraphPad Prism 7 software.

\section{Results}

\section{RhBMP-2 dose response of model cell lines}

The induction of ALP in W-20-17, C2C12, and MC3T3 cells was compared as a function of the concentration of an

*Cardillo G. Four parameters logistic regression-There and back again. 2012. https://it.mathworks.com/matlabcentral/fileexchange/ 38122 


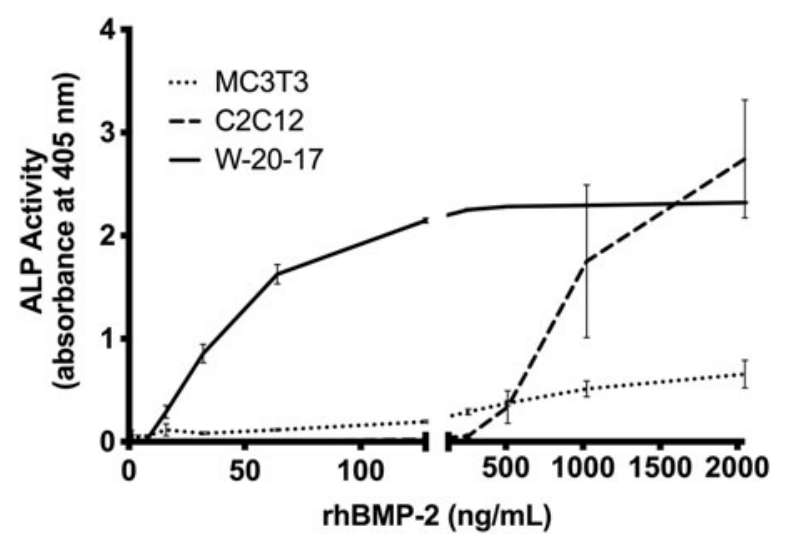

FIG. 1. Dose response of rhBMP-2 in different model cell lines. The activity of rhBMP-2 (obtained from ECUST) was measured in C2C12 (dashed), MC3T3 (dotted), or W-20-17 cells (solid) after $72 \mathrm{~h}$ ( 3 days). Dose ranges from 1 to $2048 \mathrm{ng} /$ $\mathrm{mL}$ with twofold dilutions were tested in all three cell lines. Data presented as average \pm SE $(n=4)$. ECUST, East China University of Science and Technology; rhBMP-2, recombinant human bone morphogenetic protein-2; SE, standard error.

E. coli-derived rhBMP-2 obtained from ECUST. After $72 \mathrm{~h}$ of incubation with a concentration range of $1-2048 \mathrm{ng} / \mathrm{mL}$ of rhBMP-2, ALP induction was measured with PNPP as a substrate (Fig. 1). C2C12 cells have a detection limit of $\sim 200 \mathrm{ng} / \mathrm{mL}$, and show a strong dose response at concentrations $>500 \mathrm{ng} / \mathrm{mL}$ and up to the highest concentration of rhBMP-2 used in this study. MC3T3 cells have a lower detection limit at $\sim 60 \mathrm{ng} / \mathrm{mL}$, but the MC3T3 cellbased assay is less sensitive to variations in rhBMP-2 concentration and may therefore be a less desirable assay when accurate quantification is required. W-20-17 cells show the greatest sensitivity, with a detection limit at $10 \mathrm{ng} / \mathrm{mL}$. A sharp dose-dependent response is observed up to $100 \mathrm{ng} / \mathrm{mL}$, after which the signal reached saturation.

\section{Effect of incubation time on rhBMP-2 dose response}

Incubation time with rhBMP-2 is another variable reported in the literature, with many studies reporting incubation times ranging from 1 to 7 days. ${ }^{15-18}$ The kinetics of ALP expression in response to rhBMP-2 induction may be different in dif-

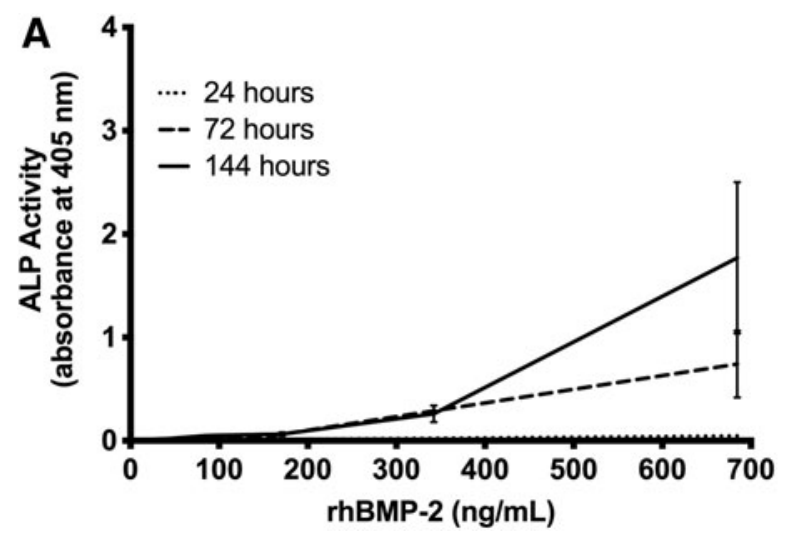

ferent cell lines. To evaluate the effect of incubation time on the response to rhBMP-2, we compared the dose-dependent responses of $\mathrm{C} 2 \mathrm{C} 12$ and $\mathrm{W}-20-17$ cells to the same E. coliderived rhBMP-2 as used before using a lower range of concentrations from 0 to $684.5 \mathrm{ng} / \mathrm{mL}$ (Fig. 2). As shown in Figure 2A, $24 \mathrm{~h}$ of incubation with rhBMP-2 resulted in little ALP activity in the $\mathrm{C} 2 \mathrm{C} 12$ cell line. Increasing the incubation time to 3 and 6 days increased the response at the highest concentrations $(684.5 \mathrm{ng} / \mathrm{mL})$, but did not improve the sensitivity of the cell line at lower concentrations.

A different effect of incubation time was observed for W-2017 cells. A 24-h incubation with the same low concentration range of rhBMP-2 increased the sensitivity of the W-20-17 cell line, as the detection limit was reduced to $\sim 2 \mathrm{ng} / \mathrm{mL}$ (Fig. 2B). The slope of the linear response range decreased, making the cell line more responsive over a wider range of concentrations but less sensitive to small differences in concentration. As incubation time increased to 3 and 6 days, the detection limit increased, but the slope of the linear range also increased, indicating an even narrower range of sensitivity.

\section{Comparison of commercially available rhBMP-2}

We next used the W-20-17 cell line to compare the bioactivity of rhBMP-2 obtained from different commercial sources, CHO-derived rhBMP-2 (C1, C2, C3), E. coliderived rhBMP-2 (E1, E2, E3), and HEK-293-derived rhBMP-2 (H1) (Fig. 3). As shown in Figure 3A, all tested samples of E. coli-derived rhBMP-2 triggered lower levels of ALP expression as compared with all of the samples of mammalian-derived rhBMP-2. This is also reflected by the ED50 values (Fig. 3B) where higher values indicate lower bioactivity. These results confirm the common observation that mammalian cell-derived rhBMP-2 is more active in vitro than $E$. coli-derived forms of rhBMP-2. The most bioactive preparations among our test samples were $\mathrm{C} 1$ and $\mathrm{H} 1$, but the differences among all mammalian cell-derived rhBMP-2 samples were not statistically significant.

\section{Storage stability}

To define a correlation between the bioactivity of rhBMP-2 protein and protein concentration, a CHO-derived rhBMP-2 (C1) (Fig. 4A) and E. coli-derived rhBMP-2 (E3) (Fig. 4B)

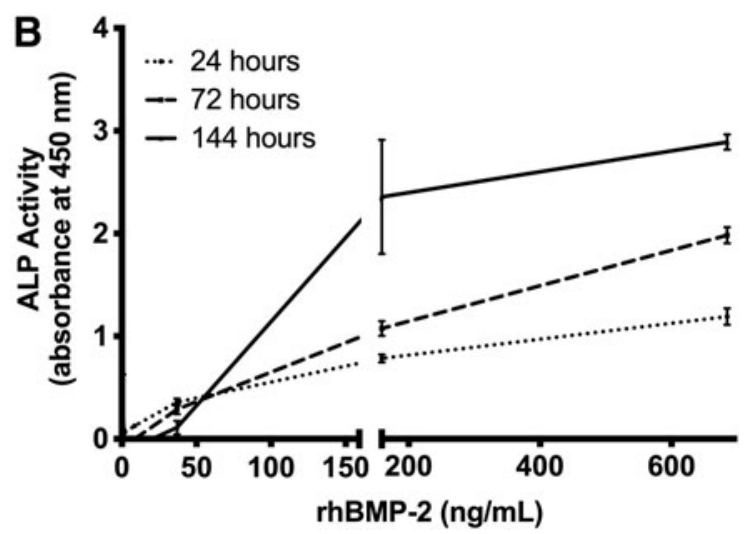

FIG. 2. Effect of incubation time on rhBMP-2 dose response. rhBMP-2 activity was evaluated at the indicated period of time in $\mathrm{C} 2 \mathrm{C} 12$ cells $(\mathbf{A})$ and $\mathrm{W}-20-17$ cells $(\mathbf{B})$ for a low concentration range of $0-684.5 \mathrm{ng} / \mathrm{mL}$ of rhBMP-2 obtained from ECUST. Data presented as average $\pm \operatorname{SE}(n=4)$. 

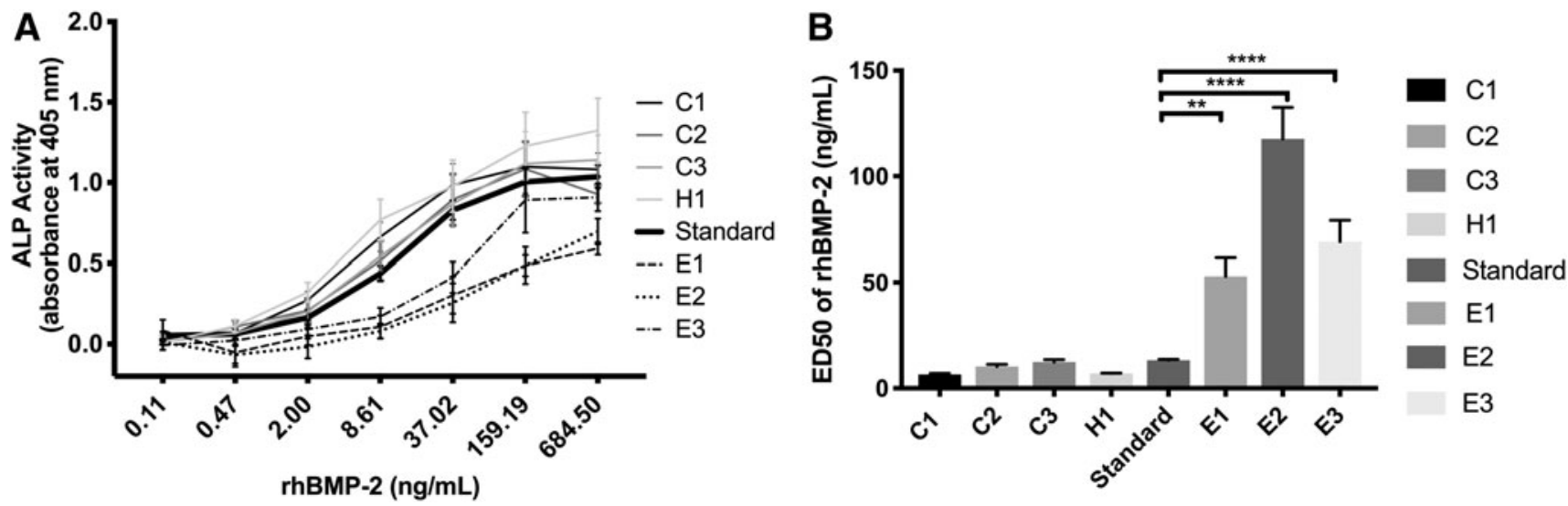

FIG. 3. Bioactivity comparison of commercially available rhBMP-2. (A) RhBMP-2 dose-response curves obtained by incubating W-17-20 cells with rhBMP-2-containing medium for $24 \mathrm{~h}$ at the concentration range of $0.1-684.5 \mathrm{ng} / \mathrm{mL}$. The international rhBMP-2 standard is indicated by the bolded line. (B) Quantification of ED50 values based on (A). Data presented as average $\pm \operatorname{SE}(n=3)$. One-way analysis of variance was performed on ED50 data, $* * p<0.01, * * * * p<0.0001$.

solution $(1 \mu \mathrm{g} / \mathrm{mL})$ were incubated in the assay medium of $\mathrm{W}$ 20-17 cells at $37^{\circ} \mathrm{C}$ for up to 14 days. Both bioactivity and protein concentration in the assay medium were measured at different time points (Fig. 4). For C1 (Fig. 4A) and E3 (Fig. 4B), the decrease of bioactivity followed the decrease in rhBMP-2 concentration. These results indicate that the change of rhBMP2 concentration can be used as an approximate indicator of a change in bioactivity. This may be useful in some experimental designs since it is easier to determine rhBMP-2 concentration by ELISA than bioactivity by ALP expression.

To determine the storage stability of different rhBMP-2 preparations, the concentrations of the different rhBMP-2 proteins in solution were measured by ELISA over time (Fig. 5). We expected that the ELISA-measured concentrations of rhBMP-2 would decrease over time. This basic behavior was indeed observed for all tested samples with the exception of the HEK-derived rhBMP-2 (H1), which showed an unexpected degree of stability throughout the incubation time (Fig. 5C). Figure 5A and B show sample-specific variations in storage stability at $37^{\circ} \mathrm{C}$. There seems to be a general trend that the half-life of E. coli-derived BMP-2 (except for E3) was longer compared with $\mathrm{CHO}$-derived BMP-2 (Fig. 5B). However, we did not find generally applicable correlations between storage stability and the source of rhBMP-2, indicating that the storage stability of any given sample of rhBMP-2 needs to be verified.

\section{Discussion}

Since rhBMP-2 is expressed in different biological systems and may come from different manufacturing processes, its bioactivity has to be measured and reported to facilitate the comparison of results from different laboratories. Further, for comparative studies, a generally accepted bioactivity assay (used at a uniform concentration of rhBMP-2) is critically needed. Here, we report, for the first time, a direct comparison of different bioactivity assay parameters and an evaluation of the advantages and disadvantages of each assay. In addition, we compare the bioactivity of commercially available preparations of rhBMP-2 with an international standard, and assess the effect of glycosylation on the stability of rhBMP-2s during incubation under physiological conditions.

Currently, in the literature, different cell lines (i.e., C2C12, W-20-17, and MC3T3) and varying assay incubation times have been used to measure bioactivity of rhBMP-2. The varying responses from the three different model cell lines (Fig. 1) highlight the importance of choosing the proper cell line when evaluating rhBMP-2 bioactivity in vitro. Each cell
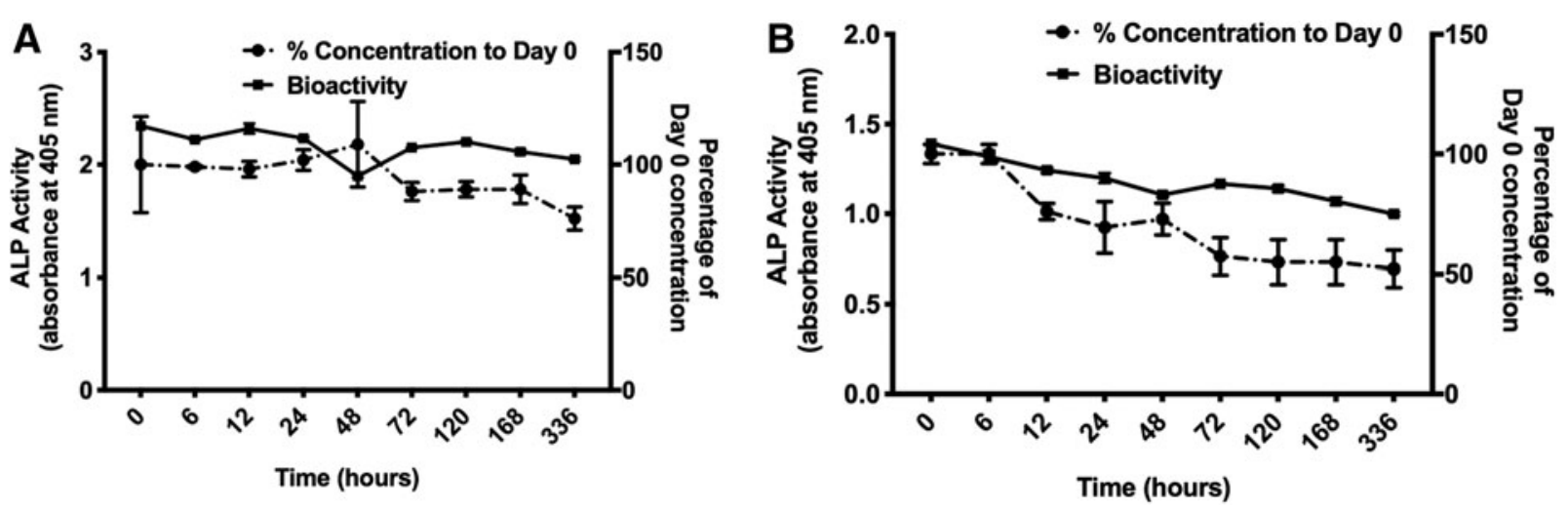

FIG. 4. Stability of rhBMP-2 at $37^{\circ} \mathrm{C}$ over time. Concentration of rhBMP-2 in the medium was quantified using ELISA (dashed), and bioactivity by ALP induction was measured in response to rhBMP-2 stimulation (solid). CHO-derived rhBMP-2 (C1) (A) and Escherichia coli-derived rhBMP-2 (E3) (B) were tested using W-20-17 cells. Data presented as average \pm SE $(n=3)$. ALP, alkaline phosphatase; CHO, Chinese hamster ovary; ELISA, enzyme-linked immunosorbent assay. 

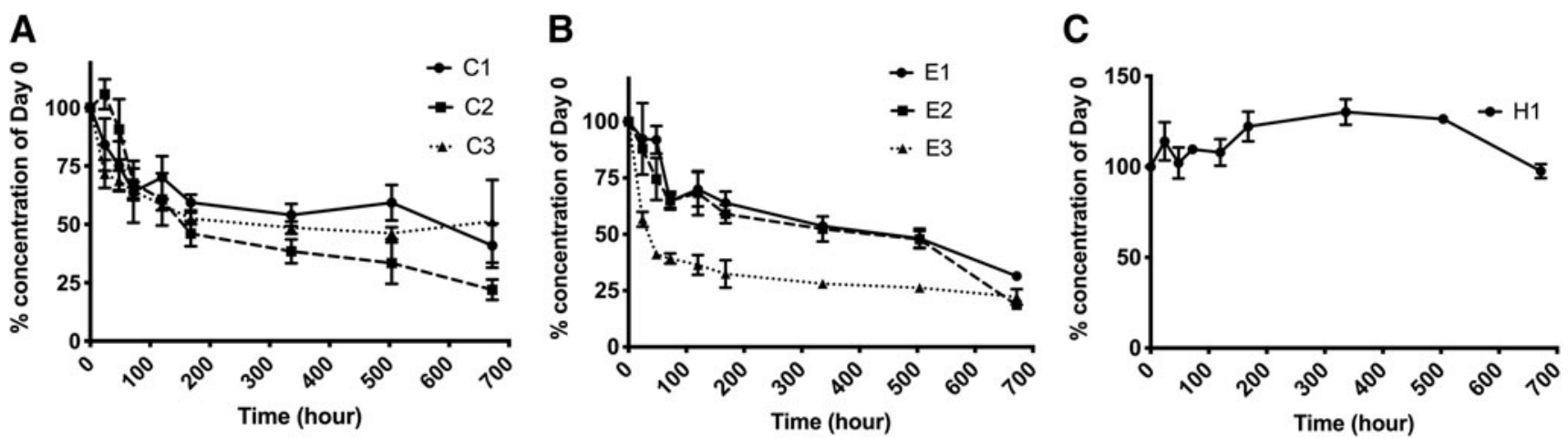

FIG. 5. Stability of commercially available rhBMP- 2 at $37^{\circ} \mathrm{C}$. Concentration of $\mathrm{CHO}$ cell-derived rhBMP-2 (A), E. coliderived rhBMP-2 (B), and HEK-derived rhBMP-2 (C) at the indicated time points. The concentration was quantified by ELISA and normalized to that of day 0 . Data are presented as average \pm SE $(n=3)$. HEK, human embryonic kidney.

line analyzed in this study shows different rhBMP-2 response kinetics, making them suitable for different applications. The ASTM Standard (F2131-02) uses the W-20-17 mouse stromal cell line, which has a very low detection limit of $2 \mathrm{ng} / \mathrm{mL}$. This assay is best when rhBMP-2 is present only in low concentrations. ${ }^{10,13,14} \mathrm{C} 2 \mathrm{C} 12$ cells show little response at concentrations $<200 \mathrm{ng} / \mathrm{mL}$ in agreement with previous reports, ${ }^{1,15-18}$ but a much greater response at higher concentrations (>500 ng/ $\mathrm{mL}$ ), a range at which the $\mathrm{W}-20-17$ cells have already saturated in their signal output.

C2C12 cells express constitutively high levels of Msx2, which suppresses the mRNA and enzymatic activity levels of ALP induced by rhBMP-2. ${ }^{22}$ This explains why these cells require higher concentrations of rhBMP-2 to overcome the Msx2 suppression of ALP activity. As a myoblast cell line, the use of these cells to evaluate rhBMP-2 bioactivity can give key insight into the consequences of using rhBMP-2 above a certain concentration in vivo. The MC3T3 cells express a higher basal level of ALP activity compared with C2C12 and W-2017 cells, and ALP is not upregulated to the same extent upon induction with rhBMP-2. However, the range over which the cells respond is much broader than either the $\mathrm{C} 2 \mathrm{C} 12$ or $\mathrm{W}-20$ 17 cells, making it a better cell line to use if studying systems that take advantage of a broad concentration range.

After choosing the W-20-17 cell line as the model cell line of choice and a 24-h incubation as the incubation time, we validated the method using rhBMP-2 from commercial sources. The comparison of the commercially available BMP-2s with an international standard highlights the importance of the expression system used to produce the recombinant protein. The mammalian cell-derived rhBMP-2 had consistently lower ED50 values (higher bioactivity) than the E. coli-derived rhBMP-2.

The glycosylated form of the protein produced in mammalian cells is more hydrophilic, and the post-translational modification plays an important role in the recognition of the protein by the cells. ${ }^{23,24}$ On the contrary, it is worth noting that some studies demonstrate that $E$. coli-derived rhBMP-2 is able to trigger higher healing in vivo. This is probably because the lack of glycosylation increases the retention of E. coli-derived rhBMP-2 within the implanted carrier in vivo compared with that of the $\mathrm{CHO}$-derived protein. ${ }^{25}$

We demonstrated that there is a correlation between rhBMP2 bioactivity measured by ALP induction and rhBMP- 2 concentration measured by ELISA. Therefore, the convenient measurement of rhBMP-2 concentration by ELISA can be used to obtain an estimate of the bioactivity of the protein, assuming that rhBMP-2 is losing its bioactivity through denaturation or degradation that will render the epitopes unrecognizable by the antibodies of an ELISA.

\section{Conclusion}

We determined the different dose-responsive behaviors of W-20-17, MC3T3, and C2C12 cell lines. Among those cell lines, W-20-17 cells used as described in ASTM Standard (F2131-02) had the lowest limit of detection with a desirable dose-dependent response when low concentrations of rhBMP-2 are present. C2C12 cells have a detection limit of $\sim 200 \mathrm{ng} / \mathrm{mL}$, and show a strong dose response at concentrations $>500 \mathrm{ng} / \mathrm{mL}$ and up to $\sim 2000 \mathrm{ng} / \mathrm{mL}$, the highest concentration of rhBMP-2 used in our study.

A bioactivity assay using $\mathrm{C} 2 \mathrm{C} 12$ cells may be ideal when rhBMP-2 is present in higher concentrations and could be used, for example, as a quality test during the production of rhBMP-2 batches. Bioactivity assays using MC3T3 cells have a detection limit at $\sim 60 \mathrm{ng} / \mathrm{mL}$, but the MC3T3 cellbased assay is less sensitive to variations in rhBMP-2 concentration. On the contrary, incubation time is an important variable in all cell-based bioactivity assays. Assays based on $\mathrm{C} 2 \mathrm{C} 12$ cells gave optimal results at long incubation times of up to 6 days, while assays using W-20-17 cells performed well for all incubation times ranging from $24 \mathrm{~h}$ to 6 days.

We observed that rhBMP-2 generated from mammalian cells showed overall higher bioactivity than that from E. coli. Moreover, we established a relationship between bioactivity as measured by ALP induction and rhBMP-2 concentration as measured by ELISA. Therefore, concentration of rhBMP2 being released from a delivery vehicle within the cellular dose-responsive range can be used as an indicator of rhBMP2 bioactivity. Our results provide guidance for the establishment of suitable assays for the measurement of rhBMP-2 bioactivity under a wide range of experimental conditions.

\section{Acknowledgments}

We extend our appreciation to Professor Changsheng Liu from East China University of Science and Technology for providing rhBMP-2. We are also grateful to Dr. Lour Serrano De La Pena for her comments on an earlier version of the article. 


\section{Funding Information}

This work was supported by the Army, Navy, NIH, Air Force, VA, and Health Affairs to support the AFIRM II effort under Award No. W81XWH-14-2-0003. The U.S. Army Medical Research Acquisition Activity, Fort Detrick, MD is the awarding and administering acquisition office. Opinions, interpretations, conclusions, and recommendations are those of the author and are not necessarily endorsed by the Department of Defense.

Research reported in this publication was also supported by the National Institute of Biomedical Imaging And Bioengineering of the National Institutes of Health under Award Number P41EB001046. The content is solely the responsibility of the authors and does not necessarily represent the official views of the National Institutes of Health.

\section{References}

1. Katagiri, T., Yamaguchi, A., Komaki, M., et al. Bone morphogenetic protein-2 converts the differentiation pathway of $\mathrm{C} 2 \mathrm{C} 12$ myoblasts into the osteoblast lineage. J Cell Biol 127, 1755, 1994.

2. Yamaguchi, A., Katagiri, T., Ikeda, T., et al. Recombinant human bone morphogenetic protein-2 stimulates osteoblastic maturation and inhibits myogenic differentiation in vitro. J Cell Biol 113, 681, 1991.

3. Ebara, S., and Nakayama, K. Mechanism for the action of bone morphogenetic proteins and regulation of their activity. Spine (Phila Pa 1976) 27, S10, 2002.

4. Wozney, J.M., Rosen, V., Celeste, A.J., et al. Novel regulators of bone formation: molecular clones and activities. Science 242, 1528, 1988.

5. Gautschi, O.P., Frey, S.P., and Zellweger, R. Bone morphogenetic proteins in clinical applications. ANZ J Surg 77, 626, 2007.

6. Scheufler, C., Sebald, W., and Hulsmeyer, M. Crystal structure of human bone morphogenetic protein-2 at $2.7 \mathrm{~A}$ resolution. J Mol Biol 287, 103, 1999.

7. Kubler, N.R., Reuther, J.F., Faller, G., Kirchner, T., Ruppert, R., and Sebald, W. Inductive properties of recombinant human BMP-2 produced in a bacterial expression system. Int J Oral Maxillofac Surg 27, 305, 1998.

8. Demain, A.L., and Vaishnav, P. Production of recombinant proteins by microbes and higher organisms. Biotechnol Adv 27, 297, 2009.

9. Kim, I.S., Lee, E.N., Cho, T.H., et al. Promising efficacy of Escherichia coli recombinant human bone morphogenetic protein-2 in collagen sponge for ectopic and orthotopic bone formation and comparison with mammalian cell recombinant human bone morphogenetic protein-2. Tissue Eng Part A 17, 337, 2011.

10. Kisiel, M., Ventura, M., Oommen, O.P., et al. Critical assessment of rhBMP-2 mediated bone induction: an in vitro and in vivo evaluation. J Control Release 162, 646, 2012.

11. Schmoekel, H., Schense, J.C., Weber, F.E., et al. Bone healing in the rat and dog with nonglycosylated BMP-2 demonstrating low solubility in fibrin matrices. J Orthopaed Res 22, 376, 2004.

12. Thies, R.S., Bauduy, M., Ashton, B.A., Kurtzberg, L., Wozney, J.M., and Rosen, V. Recombinant human bone morphogenetic protein-2 induces osteoblastic differentiation in W-20-17 stromal cells. Endocrinology 130, 1318, 1992.

13. Kim, S., Kang, Y.Q., Krueger, C.A., et al. Sequential delivery of BMP-2 and IGF-1 using a chitosan gel with gelatin microspheres enhances early osteoblastic differentiation. Acta Biomater 8, 1768, 2012.

14. Kempen, D.H.R., Lu, L., Hefferan, T.E., et al. Retention of in vitro and in vivo BMP-2 bioactivities in sustained delivery vehicles for bone tissue engineering. Biomaterials 29, 3245, 2008.

15. Hanseler, P., Jung, U.W., Jung, R.E., et al. Analysis of hydrolyzable polyethylene glycol hydrogels and deproteinized bone mineral as delivery systems for glycosylated and non-glycosylated bone morphogenetic protein-2. Acta Biomater 8, 116, 2012.

16. Zhou, H., Qian, J., Wang, J., et al. Enhanced bioactivity of bone morphogenetic protein-2 with low dose of 2-N, 6-Osulfated chitosan in vitro and in vivo. Biomaterials 30, 1715, 2009.

17. Smith, E., Yang, J., McGann, L., Sebald, W., and Uludag, H. RGD-grafted thermoreversible polymers to facilitate attachment of BMP-2 responsive $\mathrm{C} 2 \mathrm{C} 12$ cells. Biomaterials 26, 7329, 2005.

18. Crouzier, T., Sailhan, F., Becquart, P., Guillot, R., LogeartAvramoglou, D., and Picart, C. The performance of BMP-2 loaded TCP/HAP porous ceramics with a polyelectrolyte multilayer film coating. Biomaterials 32, 7543, 2011.

19. Takuwa, Y., Ohse, C., Wang, E.A., Wozney, J.M., and Yamashita, K. Bone morphogenetic protein-2 stimulates alkaline phosphatase activity and collagen synthesis in cultured osteoblastic cells, MC3T3-E1. Biochem Biophys Res Commun 174, 96, 1991.

20. Hiraki, Y., Inoue, H., Shigeno, C., et al. Bone morphogenetic proteins (BMP-2 and BMP-3) promote growth and expression of the differentiated phenotype of rabbit chondrocytes and osteoblastic MC3T3-E1 cells in vitro. J Bone Miner Res 6, 1373, 1991.

21. Krishnan, L., Priddy, L.B., Esancy, C., et al. Delivery vehicle effects on bone regeneration and heterotopic ossification induced by high dose BMP-2. Acta Biomater 49, 101, 2017.

22. Kim, Y.J., Lee, M.H., Wozney, J.M., Cho, J.Y., and Ryoo, H.M. Bone morphogenetic protein-2-induced alkaline phosphatase expression is stimulated by Dlx 5 and repressed by Msx2. J Biol Chem 279, 50773, 2004.

23. Hang, Q.L., Zhou, Y., Hou, S.C., et al. Asparagine-linked glycosylation of bone morphogenetic protein-2 is required for secretion and osteoblast differentiation. Glycobiology 24, 292, 2014.

24. Ohtsubo, K., and Marth, J.D. Glycosylation in cellular mechanisms of health and disease. Cell 126, 855, 2006.

25. Uludag, H., D’Augusta, D., Golden, J., et al. Implantation of recombinant human bone morphogenetic proteins with biomaterial carriers: a correlation between protein pharmacokinetics and osteoinduction in the rat ectopic model. J Biomed Mater Res 50, 227, 2000.

Address correspondence to: Joachim Kohn, PhD New Jersey Center for Biomaterials Rutgers-The State University of New Jersey 145 Bevier Road Piscataway, NJ 08854

E-mail: kohn@dls.rutgers.edu

Received: June 15, 2019

Accepted: August 12, 2019

Online Publication Date: September 18, 2019 